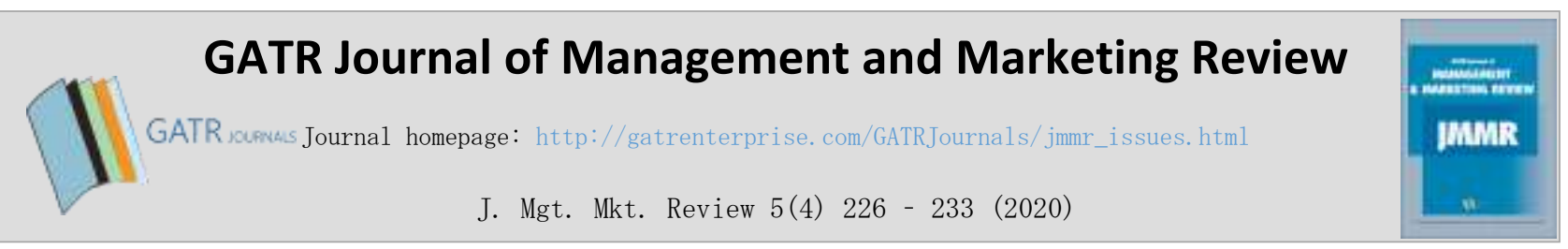

\title{
A Conjoint Analysis of Consumer Preferences for Chili Products: A Case Study on Chili Sauce
}

\author{
Premruedee Jitkuekul $^{1 *}$, Sirinna Khamtanet ${ }^{2}$ \\ ${ }^{1,2}$ Kasetsart University, Sakonnakhon, Thailand
}

\begin{abstract}
Objective - This study aimed to investigate Thai customers' preference to chili sauce using conjoint analysis (henceforth CA).

Methodology/Technique - The participants of the study were residents of Sakon Nakhon, Nakhon Phanom and Mukdahan, Thailand. Data were collected with a stratified sampling technique and 420 usable questionnaires were considered.

Findings -The participants of the study were residents of Sakon Nakhon, Nakhon Phanom and Mukdahan, Thailand. Data were collected with a stratified sampling technique and 420 usable questionnaires were considered. Conjoint Analysis indicates that consumers attach the most importance to a reasonable price, which is 45 baht. Since price is related to quality, good quality products must have a reasonable price. The flavor is the second priority. Consumers tend to prefer a hot \& sweet flavor, yet too hot is not ideal, hot should be combined with a sweet flavor to make it smoother. In addition, consumers prefer a combination of herbal ingredients with organic chili, given the growing healthy trend in Thailand. Consumers then prefer an organic chili sauce with herbal ingredients that promotes good health. In terms of packaging, consumers prefer a squeezable product, rather than a bottle.

Novelty - This paper will study the preferences of consumers with regards to the product; not much research on these topics has been undertaken. It could assist the company in knowing how to produce the product to respond to the customer's demand.
\end{abstract}

Type of Paper: Empirical.

JEL Classification: M31, M39.

Keywords: Chili sauce; Conjoint analysis; Consumer preferences; Customer satisfaction; New product development

Reference to this paper should be made as follows: Jitkuekul, P; Khamtanet, S. (2020). A Conjoint Analysis of Consumer Preferences for Chili Products: A Case Study on Chili Sauce, J. Mgt. Mkt. Review, 5(4) 226 - 233. https://doi.org/10.35609/jmmr.2020.5.4(4)

\section{Introduction}

Chili is a spice typically grown globally, including in Thailand, for either domestic consumption or commercial purposes. If considered in terms of economic perspectives, growing chili can help farmers earn some income as well as becoming a prosperous business for retailers. Moreover, chili is a major ingredient for the processed food and medicine industries, with profits gained by exporting it overseas.

\footnotetext{
Paper Info: Revised: September 29, 2020

Accepted: December 31, 2020

* Corresponding author: Premruedee Jitkuekul

E-mail: premrudee.ch@ku.th

Affiliation: Kasetsart University, Sakonnakhon, Thailand
} 
Thailand has a 5.44 percentage market share of chili worldwide with its chili products exported overseas, namely, green and red chili, dried chili and ground chili, as well as chili dips for chicken, chili paste and curry paste. These exports are expected to increase for the purpose of serving those who favor Thai food in foreign countries (Senadee, Pomrit, \& Chaiyaporn, 2018). In Thailand, growing and cultivating chili ranks fifth in the world, as the plant is grown in a total land area of 575,787.5 Rai (FAO, 2016), which yields 332,888 tons of fresh chili. Northeastern Thailand is an area where most chili is grown, accounting for about 37 percent of total production. There, a total land area of 128,932 Rai yields 117,150 tons of fresh chili (DOAE, 2019) . When formulating the agricultural policy of Thailand, growing chili is normally promoted. The major goal for chili production in the country particularly concerns how to have a product that serves various markets. However, there has been limited development of chili products in Thailand, as well as changing needs of consumers, who want something different and are willing to pay more for a product of suitable quality (Mennecke, Townsend, Hayes, \& Lonergan, 2007). Product improvement and development create value for the product. It is the key for continuously enabling the business; however, product development process demands information to make decisions with regards to the requirements of customers.. If products do not match with client specification, companies waste a lot of money in product development process. Therefore, new product development is necessary to know the key features that customers are interested in for the products.

This research will study factors that influence decisions to buy chili products. To explore the question and answer it, a marketing approach is widely used (Kessels, Goos, \& Vandebroek, 2008), hence conjoint analysis is introduced here as it is useful for market surveys and the development of commodities for daily use. Conjoint analysis has recently been used for agricultural products and this has resulted in adjustments to products to better suit consumers' needs (Alriksson \& Öberg, 2008). Research outcomes provide useful information about the utility importance of product attributes, such as flavor, price, size, packaging, herbal ingredients, and organic chili, which might be associated with a particular chili sauce. According to results from this study, the research expands the knowledge of customers' preference for chili sauce, which is rarely surveyed. Also, the research helps the chili sauce company to understand what customers are interested in when they purchase chili sauce. Based on results, the company is able to design products to meet customers' expectation; as a result, the company has a competitive advantage and reduces the cost of product development.

\section{Literature Review}

\subsection{Conjoint analysis}

There is evidence that conjoint analysis (henceforth CA) plays a crucial role in analyzing peoples' preference for the product. This method had been used in marketing research for 40 years (Green \& Srinivasan, 1978). CA has been applied in a variety of applications such as new product development, product improvement, pricing, advertising, distribution channel, and market segmentation (Alriksson \& Öberg, 2008). A principal concept of CA was adopted from Lancaster's characteristics theory of demand. The CA approach refers to the utility or satisfaction consumers received, which is caused by each attribute, more than by the satisfaction produced by the use of the product. (Green \& Srinivasan, 1978; Green \& Srinivasan, 1990). Many researchers stated that customer decision making is based on product attributes, so the evaluation of the physical characteristics of the product is the key for decision making (Alriksson \& Öberg, 2008; De Pelsmaeker, Dewettinck, \& Gellynck, 2013). Attribute theory results in the purchasing pattern of the product. Green and Srinivasan $(1978,1990)$ have mentioned that the customer is preferring to buy products based on the product attributes rather than its benefits. Lancaster (1966) also argued that the attributes of the product may influence the customers' decision making of the product. In his discussion of the attributes model, he explains how the customers' purchasing decision making is based on the product's characteristics. . Those characteristics include the physical characteristic of the product. Lancaster (1966) identifies two characteristics of customers' process of purchasing of the product: relevant characteristics and 
irrelevant characteristics. Relevant characteristics can broadly be defined as the product attributes could have an effect on the customer's decision making of purchasing the product. Similarly, if the attributes of products are changed, the decision making will be changed. Irrelevant characteristics mean that the product attributes do not affect the customers' decision making. If the attributes of products are changed, the decision making will not be changed (Deliza, Rosenthal, Hedderley, \& Jaeger, 2010).

The purpose of CA study is to compute the relative importance of the product attributes specified in the research. Each attribute consists of the level of choice which is about 2 or more. The most important of CA is the attribute that the product be reasonably priced, and there must be clarity to enable customers to distinguish between different products. (Alriksson \& Öberg, 2008). Therefore, CA will list the customer preferences at each attribute level based on the respondents' liking of each attribute (Gustafsson, Ekdahl, \& Bergman, 1999). A utility score demonstrates the attractiveness of each option at different levels in the attribute of this study. A high level of utility will represent the level of attribute that affects the customer preference, which the importance score derived from the total attribute multiplied by 100 (Orme, 2014). According to the equation below, we can assume that there is a linear relationship between satisfaction and the utility.

$\mathrm{Y}=\beta_{0}+\beta_{1} x_{1}+\beta_{2} x+\beta_{3} x_{3}+\cdots+\beta_{i} x_{j}$ where as

Y=Total attribute $\quad \beta_{i}=$ Utility Coefficient of attribute I $\quad x_{j}=$ Attribute $\mathrm{j}$

\section{Research Methodology}

\subsection{Data collection}

The participants of the study were residents who live in three provinces: Sakon Nakhon, Nakhon Phanom and Mukdahan, Thailand. Data were collected and analyzed using stratified sampling technique. Also, 420 usable questionnaires were considered. There are four steps used in the data collection.

Firstly, 15 participants were chosen from the population of focus group that used as a method to choose attributes for this study. six characters of the attributes were chosen to create questions. Those are flavor, price, size packaging, herbal ingredients, and organic chili (as shown in Table 1 below). Secondly, concept cards were created by a statistical program with orthogonal design. Thirdly, data collection. There were 420 samples included in this study. Then, we used the questionnaire to collect the data based on the product's attributes. All participants were given a questionnaire that comprises of product attributes in each scenario, 20 scenarios in total (four holdouts include). The participants were asked to rate their satisfaction towards each scenario. Finally, the dataset was calculated and analyzed, and then all analyses were carried out using a statistical program.

\subsection{Data analysis}

Conjoint Analysis (CA) is a tool widely used in marketing work in which consumers are allowed to evaluate their favorite products and services and each of their attributes (Backhaus, Wilken, \& Hillig, 2007; Hair, Black, Babin, \& Anderson, 2014; Kessels et al., 2008). In other words, this approach enables consumers to evaluate their favorites according to a set of product profiles consisting of different attributes at various levels (Green \& Srinivasan, 1978; Pe ntina, Prybutok, \& Zhang, 2008). This research used conjoint analysis to investigate a chili sauce product's attributes that affect customer satisfaction and lead to decisions to buy the product. To further enhance the external validity of the research, an additional six attributes are presented here, namely, flavor, price, size, packaging, herbal ingredients, and organic chili. This study was designed as a fractional factorial of six attributes with four holdouts. Three attributes were arranged with three levels (flavor, price and size), and three attributes were arranged with two levels (packaging, herbal ingredients and organic chili). 


\section{Results}

77.4 percent of the sample consisted of respondents who were aged between 21-40 years old. Just over half the sample (54.5\%) was female. The participants' educational level was a bachelor's degree (61\%), and the salary was ranged between 15,001-25,000 Baht (35.2\%).

The method used in this current study was based on the attributes model. The six attributes of customers' preference of chili sauce were employed: flavor, price, size, packaging, herbal ingredients and being organic of the chili sauce. This method was used to see whether the model is discrete or non-correlated. All attributes were analyzed by a statistical program of conjoint analysis function, as can be seen from the output in Table 1 .

Table 1 represents the analyses of the preference model to product attributes in the customers' decision making of chili sauce purchase.

\begin{tabular}{|c|c|c|c|c|}
\hline Attributes & Level of Attribute & Utility & Standard Error & Important (\%) \\
\hline \multirow[t]{3}{*}{ Flavors } & A hot \& sweet chili & 0.084 & 0.062 & \multirow[t]{3}{*}{20.891} \\
\hline & A mild \& slightly sweet chili & 0.012 & 0.058 & \\
\hline & A hot chili & -0.096 & 0.064 & \\
\hline \multirow[t]{3}{*}{ Price } & 25 Baht & 0.055 & 0.059 & \multirow[t]{3}{*}{36.043} \\
\hline & 45 Baht & 0.493 & 0.063 & \\
\hline & 55 Baht & -0.549 & 0.074 & \\
\hline \multirow[t]{3}{*}{ Size } & $230 \mathrm{~g}$ & 0.065 & 0.068 & \multirow[t]{3}{*}{9.468} \\
\hline & $300 \mathrm{~g}$ & 0.290 & 0.073 & \\
\hline & $600 \mathrm{~g}$ & -0.354 & 0.0067 & \\
\hline \multirow{2}{*}{ Pack material } & Glass & -0.042 & 0.047 & \multirow[t]{2}{*}{14.155} \\
\hline & Squeezable & 0.042 & 0.047 & \\
\hline \multirow{2}{*}{$\begin{array}{c}\text { Herbal } \\
\text { ingredients }\end{array}$} & Herbal ingredients & 0.225 & 0.050 & \multirow[t]{2}{*}{5.149} \\
\hline & Not herbal ingredients & -0.225 & 0.050 & \\
\hline \multirow[t]{2}{*}{ Organic } & Organic & 1.107 & 0.060 & 14.295 \\
\hline & Not organic & -1.107 & 0.060 & \\
\hline Constant & & 5.844 & 0.065 & 100 \\
\hline Kendall's (sig) & \multicolumn{2}{|l|}{$0.966(0.000)$} & Pearson'R (sig) & $0.996(0.000)$ \\
\hline
\end{tabular}

From table 1, the model's goodness of fit test is analyzed with Pearson's R and Kendall's Tua technique, which indicate correlation values between the predicted preference values of the model and the preference values of participants. It shows a Significant value of less than 0.005 , meaning that the attributes affect consumer decisions to buy chili sauce. Pearson's $\mathrm{R}=0.996$, indicating the model relates to satisfaction with an accuracy of 99 percentage, and Kendall's Tua $=0.966$, indicating the model can predict consumer responds' satisfaction with an accuracy of 96.6 percentage. The important value refers to the percentage of preference to each attribute with a total value of $100 \%$. The attribute can be considered one of the most important values that gained the greatest customer preference.

The most important attribute affecting consumer preferences or consumers' decisions to buy chili sauce in the upper northeastern region is price, with a value of 36.043 percentage, followed by flavor with a value of 20.891 percentage. Simultaneously, organic chili has an importance value of 14.295 percentage, packaging 14.155 percentage, size 9.468 percentage and herbal ingredients 5.149 percentage. As can be seen from table 1 , the utility value refers to the degree of preference for each attribute value. From this data, we can see that it resulted in more value of utility regarding the preference of chili sauce purchase. Table 1 provides the value of the attribute of the flavor of chili sauce.

It indicated that the hot and sweet chili was the most favorite flavor, the utility was 0.084 . While the hot chili flavor was the least preference rated by the customers which shows the utility value at -0.096 . The price 
also was rated the most value, and it showed that the preferred price was 45 Baht (utility value at 0.493 ). The least preference of chili price was at 55 Baht (utility value at - 0.549). In term of size, the customers agreed that the favorite size was approximately 300 grams, showing the highest utility value at 0.290 . However, 600 grams of the chili size was the least preferred among the customers (utility value at -0.354). The majority of those who responded to this item felt that a squeezable packaging was the most favorite packing of the chili sauce (utility value at 0.042 ). In terms of an ingredient used in the chili sauce, it indicated that the customers prefer the use of herbal ingredients mixed in the chili sauce as the utility value was at 0.225 . Likewise, the choice of chilies that was used to make the chili sauce was preferably made with organic chilies, representing the utility value at 1.107 .

Table 2, the most suitability of the total utility analysis of consumers' decisions to buy chili of the population in the Upper North Eastern region.

\begin{tabular}{|c|c|c|}
\hline Attribute & Specification & Utility \\
\hline Flavor & A hot \& sweet chili & 0.084 \\
\hline Price & 45 Baht & 0.493 \\
\hline Size & $300 \mathrm{~g}$ & 0.290 \\
\hline Pack material & Squeezable & 0.042 \\
\hline Herbal ingredients & Herbal ingredients & 0.225 \\
\hline Organic & Organic & 1.107 \\
\hline
\end{tabular}

From table 2, the total utility analysis of consumers' decisions to buy chili sauce in the upper northeastern region can be summarized with the equation:

Maximum utility $=5.844+0.084 *($ flavor: a hot $\&$ sweet chili $)+0.493 *($ price: 45 Baht $)+0.290 *($ size: 300 grams) $+0.042 *$ (packaging: squeezable bottles) $+0.225 *$ (herbal ingredients: yes $)+1.107 *$ (organic chili: yes)

\section{Discussion}

The result of the study is the price appears to be the most relevant attribute that affects the purchasing of the product. It is interesting to note that the price of the product is commonly considered as a sensitive factor when it comes to buying goods. In accordance with the present results, previous studies have demonstrated that if the price is too low, it may raise a question regarding the product quality (Chouichom, Liao, \& Yamao, 2013). Consequently, the customer preferred the price of 45 Bahts which is considered as moderate when deciding to buy goods. These results corroborate the ideas of Kramchote Srilaong \& Kanlayanarat (2001), who suggested that businesses should charge a reasonable price. These results further support the idea of Geng, Cheng, Wei, \& Zhou (2017) that customers are willing to pay more for a good quality product. It can thus be suggested that the price of the product does not seem to affect the customers' purchase of goods provided they get a quality product. Regarding the flavor of the product, the majority of those who responded to this item felt that they preferred a hot and sweet chili. The reason was that most of the participants consume spicy flavor with a bit of sweet flavor to smooth the taste. The finding is also in line with the study from Burgess's (2014) and Jeasakul \& Suwonsichon's (2013) who found that the taste is an important factor that has an influence in goods purchasing decision making. The findings of the current study contradict the previous studies from Burgess (2014) which showed that English people who are not familiar with spicy foods tend to prefer mild chili sauce and with a blend of garlic, sugar, and lime. These results corroborate the ideas of Jeasakul and Suwonsichon (2013), who suggested that Thai consumers prefer medium spicy and sweet with a sour taste. This result may be explained by the fact that Thai consumers may have not preferred a pure spiciness of the chili, they rather prefer the spicy of the chili with a subtle blend of other tastes i.e. sweet and sour. Organicness of the chili that is used to make chili sauce was on the third range of the attributes found in this study. Prior studies that have noted the importance of willingness to pay for organic products (Garcia-Yi, 2015; Priyambodo, Harianto, \& Fariyanti, 2016; Toiba, Umberger, \& Minot, 2012). It 
can be suggested that the customers may have an awareness of the insecurity of the chemicals substance that might have added to plants. Therefore, consumers are willing to pay more for organic products.

One interesting finding is the squeezable packaging of the product was preferred rather than the glass one. It can be explained that this kind of packaging may be regarded as being easy to use. These results are in agreement with Silayoi and Speece's (2007) and Anawatchasook et al., (2009) finding which showed that consumers are likely to prefer convenient packaging because of a fast-paced lifestyle trend these days. This outcome is contrary to that of Burgess (2014), who found that the British seemed to prefer Gochujang sauce in a glass bottle rather than the plastic bottle. Regarding the size of the product, the 300 gram in size or the medium size was preferable. Most chili sauce bottles made in Thailand weigh approximately 500-680 grams. These sizes are considered as too large and it will take time to consume a bottle. If not consumed within the time, such a big proportion of the chili sauce can eventually grow mold and bacteria over time. The suggested size found in this study was 280 grams mentioned as also found in the study of Burgess's (2014). The last attribute of purchasing product is herbal ingredients that are added in the chili sauce. These findings may suggest that the herbal ingredients should be mixed in the chili sauce. Likewise, it revealed that Thai people may have been familiar with herbs since Thailand has many kinds of herbs which are used as one of the ingredients in a household cooking. These results match those observed in earlier studies. For example, Burgess (2014) studied the use of the herb as one of the cooking ingredients as in his study he found that the consumers wanted to add garlic and honey into Gochujang sauce.

\section{Conclusion}

This research aimed to study consumer preferences for chili sauce in stores. The results could enhance producers' understanding of consumer preferences. The six product attributes presented to consumers impart most consumers' preference attributes. From the results, consumer attach the most importance to a reasonable price, which is 45 Baht. Most Thai customers are sensitive to the price and often consider the product price related to the product quality. Since, price is related to quality, good quality products must have a reasonable price (Kiran, Majumdar, \& Kishore, 2012). Therefore, if a product is too cheap, consumers will feel unsure about the quality. Therefore, the process of reasonable price setting is very important for products sold in Thailand. For example, the 300-gram chili sauce package, which is sold at 45 baht, is considered a relatively high-end price. It shows that customers like the offered features of the chili sauce, such as good healthy expectation and delicious taste. The flavor is the second priority. Consumers tend to prefer a hot \& sweet flavor, yet too hot are not ideal, hot should be combined with a sweet flavor to make it smoother. Most Thai people enjoy spicy foods. However, most Thai chili sauces are spicy, sour, and slightly sweet. Thus, the taste customers prefer is the taste that is suitable for Thai people. In addition, consumers prefer a combination of herbal ingredients with organic chili, given the growing healthy trend in Thailand. Consumers then prefer an organic chili sauce with herbal ingredients that promotes good health. Recently, health care trend in Thailand has been popular; accordingly, products containing herbal ingredients or healthy ingredients is gaining popularity. Nevertheless, these ingredients are not contained in Thai chili sauce. So, the findings are very interesting, namely that the customers favor to put the herbs into the chili sauce. In terms of packaging, consumers prefer a squeezable bottle, containing 300 grams, as this is suitable for a household and convenient in use. Due to most Thai chili sauce packaged in the big glass bottles, the package causes problems when it is poured. When customers cannot pour all sauce in the bottles, the chili sauce expires. Subsequently, customers desire 300 grams package with the squeeze bottles, so the new package responds to the needs of smaller modern families who have a busy lifestyle. This contribution can be applied to related products such as ketchup, mayonnaise, and soy sauce. 


\section{References}

Alriksson, S., \& Öberg, T. (2008). Conjoint analysis for environmental evaluation. Environmental Science and Pollution Research, 15(3), 244-257.doi:10.1065/espr2008.02.479

Backhaus, K., Wilken, R., \& Hillig, T. (2007). Predicting purchase decisions with different conjoint analysis methods: A Monte Carlo simulation. International Journal of Market Research, 49(3), 341-364. https://doi.org/10.1177/147078530704900306

Burgess, P. J. (2014). Modification of a traditional Korean food product (Gochujang) to enhance its consumer acceptability as an ethnic food. Journal of Ethnic Foods, 1(1), 13-18.doi:https://doi.org/10.1016/j.jef.2014.11.005

Chouichom, S., Liao, L. M., \& Yamao, M. (2013). General Viewpoint, Perception and Acceptance of Organic Food Products among Urban Consumers in the Thai Marketplace. In Sustainable Food Security in the Era of Local and Global Environmental Change (pp. 187-201). Springer, Dordrecht.https://doi.org/10.1007/978-94-007-6719-5_12

De Pelsmaeker, S., Dewettinck, K., \& Gellynck, X. (2013). The possibility of using tasting as a presentation method for sensory stimuli in conjoint analysis. Trends in food science \& technology, 29(2), 108-115. doi:https://doi.org/10.1016/j.tifs.2012.10.001

Deliza, R., Rosenthal, A., Hedderley, D., \& Jaeger, S. R. (2010). Consumer perception of irradiated fruit: a case study using choice-based conjoint analysis. Journal of sensory studies, 25(2), 184-200.doi:https://doi.org/10.1111/j.1745459X.2009.00250.x

DOAE. (2019). Monthly crop storage and reporting system.

FAO. (2016). Asia Pacific Food Price and Policy Monitor. Retrieved from http://www.fao.org/fileadmin/templates/rap/files/APFPPM/APFPPM_-_July_2016.pdf

Garcia-Yi, J. (2015). Willingness to pay for organic and fairtrade certified yellow chili peppers. British Food Journal. https://doi.org/10.1108/BFJ-11-2013-0321

Geng, X.-h., Cheng, K.-y., Wei, A.-j., \& Zhou, Y.-h. (2017). Market Competition of Fresh Vegetables between Supermarket and Wet Market in China based on the Difference of Quality and Price. Paper presented at the 9th ASAE International Conference: Transformation in agricultural and food economy in Asia, 11-13 January 2017, Bangkok, Thailand. Proceedings. https://www.semanticscholar.org/paper/Market-Competition-of-Fresh-Vegetables-between-andXian-hui-Kai-yuan/62a4d608405f8369ad1c967aa29a48f4df588170?p2df

Green, P. E., \& Srinivasan, V. (1978). Conjoint analysis in consumer research: issues and outlook. Journal of consumer research, 5(2), 103-123. https://doi.org/10.1086/208721

Green, P. E., \& Srinivasan, V. (1990). Conjoint analysis in marketing: new developments with implications for research and practice. Journal of marketing, 54(4), 3-19.doi:https://doi.org/10.1177/002224299005400402

Gustafsson, A., Ekdahl, F., \& Bergman, B. (1999). Conjoint analysis: a useful tool in the design process. Total Quality Management, 10(3), 327-343.doi:10.1080/0954412997866

Hair, J. F., Black, W. C., Babin, B. J., \& Anderson, R. E. (2014). Multivariate data analysis: Pearson new international edition. Essex: Pearson Education Limited.

Harrison, R., Stringer, T., \& Prinyawiwatkul, W. (2002). An analysis of consumer preferences for value-added seafood products derived from crawfish. Agricultural and Resource Economics Review, 31(1203-2016-95066), 157-170. doi:10.22004/ag.econ.31392

Jeasakul, P., \& Suwonsichon, T. (2013). Buying decision factors and sensory classification of chili sauce. In Proceedings of the 51st Kasetsart University Annual Conference, Bangkok, Thailand, 5-7 February 2013. Kasetsart University.

Kessels, R., Goos, P., \& Vandebroek, M. (2008). Optimal designs for conjoint experiments. Computational statistics \& data analysis, 52(5), 2369-2387.doi:https://doi.org/10.1016/j.csda.2007.10.016

Kiran, V., Majumdar, M., \& Kishore, K. (2012). Innovation in in-store promotions: effects on consumer purchase decision. European Journal of Business and Management, 4(9).

Kramchote, S., Srilaong, V., \& Kanlayanarat, S. (2001). Perspective of Postharvest Handling Consideration of Vegetables in Thailand. Population, 1995, 1907-1999.

Mennecke, B. E., Townsend, A. M., Hayes, D. J., \& Lonergan, S. M. (2007). A study of the factors that influence consumer attitudes toward beef products using the conjoint market analysis tool. Journal of animal science, 85(10), 2639-2659.doi:10.2527/jas.2006-495

Orme, B. K. (2014). Getting Started with Conjoint Analysis: Strategies for Product Design and Pricing Research: Research Publishers LLC. 
Pentina, I., Prybutok, V. R., \& Zhang, X. (2008). The role of virtual communities as shopping reference groups. Journal of Electronic Commerce Research, 9(2), 114.

Priyambodo, A. W., \& Harianto \& Fariyanti, A. (2016). Analysis Farmer Willingness to Accept and Consumer Willingness to Pay in Batu Malang East Java. International Journal of Science and Research (IJSR), 5(11), $254-258$. DOI: $10.21275 /$ ART20162815

Senadee, W., Pomrit, P., \& Chaiyaporn, C. (2018). Keha Kan Kaset.

Silayoi, P., \& Speece, M. (2007). The importance of packaging attributes: a conjoint analysis approach. European journal of marketing.https://doi.org/10.1108/03090560710821279

Toiba, H., Umberger, W. J., \& Minot, N. (2012, July). Exploring Indonesian Consumers'willingness To Pay for HighValue Agricultural Products. In IV International Symposium on Improving the Performance of Supply Chains in the Transitional Economies 1006 (pp. 397-404). DOI: 10.17660/ActaHortic.2013.1006.50 